\title{
Association between smoking and chronic kidney disease: a case control study
}

Rabi Yacoub ${ }^{1 *}$, Habib Habib ${ }^{2}$, Ayham Lahdo ${ }^{4}$, Radwan Al Ali", Leon Varjabedian ${ }^{1}$, George Atalla ${ }^{4}$, Nader Kassis Akl ${ }^{3}$, Saleem Aldakheel ${ }^{4}$, Saeed Alahdab ${ }^{4}$, Sami Albitar ${ }^{4}$

\begin{abstract}
Background: The progression of chronic kidney disease (CKD) remains one of the main challenges in clinical nephrology. Therefore, identifying the pathophysiological mechanisms and the independent preventable risk factors helps in decreasing the number of patients suffering end stage renal disease and slowing its progression.

Methods: Smoking data was analyzed in patients with CKD throughout 2005-2009. One hundred and ninety-eight patients who had recently been diagnosed with stage three CKD or higher according to the National Kidney Foundation (NKF) 2002 Classification were studied. The control group was randomly selected and then matched with the case subjects using a computerized randomization technique. The relative risk was estimated by computing odds ratio (OR) by using multinomial logistic regression in SPSS ${ }^{\oplus}$ for Windows between the two groups.

Results: Smoking significantly increases the risk of CKD ( $\mathrm{OR}=1.6, p=0.009,95 \% \mathrm{Cl}=1.12-2.29)$. When compared to nonsmokers, current smokers have an increased risk of having CKD ( $\mathrm{OR}=1.63 p=0.02,95 \% \mathrm{Cl}=1.08-2.45)$, while former smokers did not have a statistically significant difference. The risk increased with high cumulative quantity (OR among smokers with $>30$ pack-years was $2.6, p=0.00,95 \% \mathrm{Cl}=1.53-4.41)$. Smoking increased the risk of CKD the most for those classified as hypertensive nephropathy $(\mathrm{OR}=2.85, p=0.01,95 \% \mathrm{Cl}=1.27-6.39)$ and diabetic nephropathy $(2.24, p=0.005,95 \% \mathrm{Cl}=1.27-3.96)$. No statistically significant difference in risk was found for glomerulonephritis patients or any other causes.
\end{abstract}

Conclusion: This study suggests that heavy cigarette smoking increases the risk of CKD overall and particularly for CKD classified as hypertensive nephropathy and diabetic nephropathy.

\section{Background}

Smoking, a well known risk factor for many diseases, was recently proven to play an important role in renal diseases. Studies showed that cigarette smoking is a risk factor for the development and progression of chronic kidney disease (CKD) in community [1,2]. In these studies, causes of CKD were heterogeneous, while other studies implied that the relationship between cigarette smoking and kidney impairment varied among underlying kidney diseases [3]. However, there is still uncertainty whether every kidney disease is equally vulnerable due to cigarette smoking. In this sense, further research is required.

\footnotetext{
* Correspondence: Rabiyaco@buffalo.edu

'Internal Medicine department, University at Buffalo, Grider Street, Buffalo, N. Y. 14215, USA

Full list of author information is available at the end of the article
}

Since urinary albumin is a sensitive marker of glomerular injury [4], it is conceivable that the relationship of smoking to albuminuria indicates direct or indirect renal damage induced by smoking. It is blamed for the deterioration of kidney function by increasing the risk of microalbuninuria [5], accelerating the progression from microalbuminuria to proteinuria [6,7] and as a result to diabetic nephropathy which leads to end stage renal disease (ESRD) $[6,8]$. In a prospective study with 794 patients who had non insulin dependent diabetes mellitus (NIDDM), who had no proteinuria at baseline, the relative risk of developing gross proteinuria (> $300 \mathrm{mg} /$ day) during four years of observation was 2- to 2.5-fold higher in heavy smokers when compared to subjects who had never smoked [9]. Many studies also indicate a relationship between smoking and renal function deterioration in lupus patients, polycystic kidney disease,
C Biomed Central

C 2010 Yacoub et al; licensee BioMed Central Ltd. This is an Open Access article distributed under the terms of the Creative Commons Attribution License (<url>http://creativecommons.org/licenses/by/2.0</url>), which permits unrestricted use, distribution, and reproduction in any medium, provided the original work is properly cited. 
Goodpasture, renal artery stenosis, glomerulonephritis (GN) [10-12] and proximal tubular dysfunction [13,14].

This study aims to investigate the relationship between cigarette smoking and chronic kidney disease, and its effects on each type of renal failure.

\section{Methods}

\section{Study Subjects and Data Collection}

A cross-sectional study of 198 patients with CKD and 371 healthy control subjects were matched and studied. Cases were patients admitted or referred to one of the three tertiary hospitals affiliated with Aleppo university during 2005-2009 and newly diagnosed with CKD with estimated glomerular filtration rate (eGFR) of less than $60 \mathrm{mg} /$ minute $/ 1.73 \mathrm{~m}^{2}$ (CKD stages 3-5, according to the National Kidney Foundation (NKF) 2002 classification) [15]. Patients with pre- or post-renal causes of CKD were not included in the study. The type of renal disease was determined by medical history, urinalysis, and renal biopsy. Eligibility and final diagnosis was confirmed by a university nephrologist who supervised the study. Case participants were enrolled after being approved and all were recently diagnosed with CKD. Control participants were randomly selected and then matched in gender and age from healthy people, using a computerized randomization technique based on Aleppo city national database. Eligible control subjects were people from the community who had no medical history of kidney disease, which was confirmed by normal eGFR reading (more than 90 $\mathrm{mg} /$ minute $/ 1.73 \mathrm{~m}^{2}$ ) and a urine protein creatinine ratio less than 0.15 [16]. A registered research coordinator sent invitations through the mail. All measurements were done after the participants provided verbal or written consent and answered a questionnaire which included questions regarding demographic information and history of their renal disease and smoking habit.

The U.S. National Library of Medicine, Medical Subject Headings $(\mathrm{MeSH})$ define smoking as inhaling and exhaling the smoke of tobacco or something similar to tobacco available at http://www.who.int. To reduce the probability that symptoms of early CKD are influenced by tobacco use, the classification of former versus current tobacco use was based on smoking status 5 years before the interview. Regular cigarette smoking was defined as smoking at least one cigarette per day for six months or more. Regular smokers were classified into either current regular smokers if they smoked during the last five years or former regular smokers if they quit more than five years ago. Tobacco consumption was measured with a pack per year formula.

\section{Statistical Analyses}

As an estimate of the relative risk for CKD among tobacco users compared with non-smokers, we computed odds ratios (OR) in terms of $\mathrm{SPSS}^{\circ}\left(\mathrm{IBM}^{\oplus}\right.$, Chicago IL. USA) for Microsoft Windows ${ }^{\oplus}$, using multinomial logistic regression. We studied smoking as a relative risk for CKD, and then we studied former versus current smoking for the same purpose. The next step was to determine the relative risk of smoking for each type of renal disease. We studied analgesic (aspirin or paracetamol) use, body mass index (BMI), angiotensinconverting enzyme inhibitors (ACEi) or angiotensin II receptor blockers (ARBs) use, and hypertension (HTN) as confounding factors; however these factors were excluded from the final model because their inclusion did not affect the risk estimates.

\section{Results}

One hundred and ninety-eight patients and 371 healthy participants as the control group were included. The most used tobacco form was as a cigarette, so we ignored pipe and snuff usage.

Fifty one percent of case subjects and $49 \%$ of control subjects were men (Table 1). The mean age of both groups was $45.36 \pm 15.95$ years, the case subjects' mean

Table 1 Characteristic distribution in the case and control subjects

\begin{tabular}{|c|c|c|c|c|c|}
\hline & \multicolumn{2}{|c|}{$\begin{array}{l}\text { Cases } \\
(n=198)\end{array}$} & \multicolumn{2}{|c|}{$\begin{array}{l}\text { Control } \\
(n=371)\end{array}$} & \multirow[t]{2}{*}{$P$ value } \\
\hline & $\mathrm{n}$ & $\% *$ & $\mathrm{n}$ & $\% * *$ & \\
\hline Gender & & & & & 0.57 \\
\hline Male & 102 & 51.5 & 182 & 49 & \\
\hline Female & 96 & 48.5 & 189 & 51 & \\
\hline Age (yr) & & & & & 0.96 \\
\hline $18-24$ & 30 & 15.2 & 59 & 15.9 & \\
\hline $25-34$ & 28 & 14.1 & 48 & 12.9 & \\
\hline $35-44$ & 34 & 17.2 & 55 & 14.8 & \\
\hline $45-54$ & 44 & 22.2 & 92 & 24.7 & \\
\hline $55-64$ & 40 & 20.2 & 74 & 19.9 & \\
\hline$\geq 65$ & 22 & 11.1 & 43 & 11.5 & \\
\hline \multicolumn{6}{|l|}{ Medications } \\
\hline Any HTN medication & 91 & 45.9 & 149 & 40.1 & 0.18 \\
\hline $\mathrm{ACEi}$ & 83 & 41.9 & 127 & 34.2 & 0.07 \\
\hline ARBs & 15 & 7.6 & 26 & 7 & 0.81 \\
\hline Beta blockers & 72 & 36.4 & 105 & 28.3 & 0.04 \\
\hline Analgesic & 40 & 20.2 & 70 & 18.9 & 0.70 \\
\hline $\mathrm{BMI}$ & & & & & 0.14 \\
\hline Underweight & 7 & 3.5 & 26 & 7 & \\
\hline Normal weight & 104 & 52.5 & 163 & 43.9 & \\
\hline Overweight & 56 & 28.3 & 115 & 30.9 & \\
\hline Obesity & 31 & 15.6 & 67 & 18 & \\
\hline HTN & 58 & 29.3 & 92 & 24.8 & 0.25 \\
\hline Diabetes Mellitus & 56 & 28.3 & 99 & 26.7 & 0.68 \\
\hline
\end{tabular}

*Of cases $(n=198) .{ }^{*}$ Of control $(n=371)$. 
age was $45.15 \pm 15.85$ years and the control subjects mean age was $45.47 \pm 16.00$ years.

A majority of the patients were in The National Kidney Foundation Kidney Disease Outcomes Quality Initiative (NKF KDOQI ${ }^{\mathrm{mm}}$ stage 3 and 4 [15]. Seventy percent had a creatinine level $>2 \mathrm{mg} / \mathrm{dl}$. The median overall value of the eGFR calculated by the Modification of Diet in Renal Disease (MDRD) formula was $41 \mathrm{ml} /$ $\min / 1.73 \mathrm{~m}^{2}$. Forty five and a half percent of cases had glomerulonephritis as a cause for their CKD, 28.3\% diabetic nephropathy, $13.1 \%$ hypertensive nephropathy, and 13.1\% had an unknown or other causes for CKD.

About $43 \%$ of case subjects had ever smoked cigarettes regularly compared to $32 \%$ of control subjects. Compared to never regularly smoking, former and current regular smoking significantly increased the risk of CKD (OR $=1.6$, CI 95\% 1.12-2.29, $p=0.009$ ) and $(\mathrm{OR}=1.63$, CI 95\% 1.08-2.45, $p=0.02)$, respectively. The risk of CKD did not reach a significant level for former regular smokers $(\mathrm{OR}=1.04$, CI 95\% 0.58-1.86, $p=0.8$ ). This risk was obviously increased with the tobacco consumption, with $\mathrm{OR}=2.6, \mathrm{CI} 95 \%$ 1.53-4.41, $p=0.00$ for more than 30 pack/year, and $\mathrm{OR}=2.04, \mathrm{CI}$ $95 \% 1.08-3.88, p=0.02$ for $16-30$ pack/year compared to those who had never regularly smoked (Table 2).

Table 3 presents OR for different types of CKD. Smoking was significantly associated with risk of CKD caused by hypertension $(\mathrm{OR}=2.85$, CI 95\% 1.27-6.39, $p$ $=0.01)$ and diabetic nephropathy $(\mathrm{OR}=2.24, \mathrm{CI} 95 \%$ 1.27-3.96, $p=0.005)$. This association did not reach a significant level for risk of CKD caused by glomerulonephritis $(\mathrm{OR}=1.09, \mathrm{CI} 95 \% 0.67-1.78, p=0.7)$ and the

Table 2 Smoking status and Odds ratio for chronic renal failure

\begin{tabular}{|c|c|c|c|c|c|c|}
\hline & \multicolumn{2}{|c|}{ Cases } & \multicolumn{2}{|c|}{ Control } & \multirow{2}{*}{$\begin{array}{l}\mathrm{OR}^{\dagger}(\mathrm{Cl} \\
95 \%)\end{array}$} & \multirow[t]{2}{*}{$\mathbf{P}$} \\
\hline & $\mathrm{n}$ & $\% *$ & $\mathrm{n}$ & $\% * *$ & & \\
\hline \multicolumn{7}{|c|}{ Ever regular smoking } \\
\hline No & 112 & 56.5 & 251 & 67.7 & 1 (Reference) & - \\
\hline Yes & 86 & 43.4 & 120 & 32.3 & $1.6(1.12-2.29)$ & 0.009 \\
\hline \multicolumn{7}{|c|}{ Regular smoking } \\
\hline Former & 30 & 15.1 & 43 & 11.6 & $\begin{array}{l}1.04(0.58- \\
1.86)\end{array}$ & 0.8 \\
\hline Current & 56 & 28.2 & 77 & 20.8 & $\begin{array}{l}1.63(1.08- \\
2.45)\end{array}$ & 0.02 \\
\hline \multicolumn{7}{|c|}{$\begin{array}{l}\text { No. of pack/years, } \\
\text { cigarettes }\end{array}$} \\
\hline 1-15 & 34 & 17.1 & 60 & 16.1 & $2.1(0.96-4.57)$ & 0.06 \\
\hline $16-30$ & 16 & 8 & 29 & 7.8 & $\begin{array}{l}2.04(1.08- \\
3.88)\end{array}$ & 0.028 \\
\hline$>30$ & 36 & 18.1 & 31 & 8.3 & $2.6(1.53-4.41)$ & 0.000 \\
\hline
\end{tabular}

${ }^{*}$ Of cases $(n=198) .{ }^{*}$ Of control $(n=371) .{ }^{\dagger}$ Adjusted by age and gender. other causes of CKD (OR = 1.53, CI 95\% 0.68-3.44, $p=$ $0.2)$. The control subjects were gathered from the same socioeconomic background. We did not find any influence by body mass index, hypertension and analgesic use on the final results.

\section{Discussion}

We found an important statistically significant risk of CKD caused by smoking in hypertensive nephropathy and diabetic nephropathy patients and a weak, statistically insignificant association between smoking and CKD caused by glomerulonephritis.

Many studies indicate that the deleterious effect of smoking on renal function is not merely restricted to essential hypertension and diabetic nephropathy. Some of these studies found that smoking is an independent predictor of microalbuminuria in healthy patients with primary hypertension. It is well known that urinary albumin is a sensitive marker of glomerular injury [4], and the fact that there is a relationship between smoking and albuminuria indicates direct or indirect renal damage induced by smoking. Mimran et al. [17] studied lean subjects with essential hypertension and found that the prevalence of microalbuminuria was almost double in smokers as compared to non-smokers. Same results were found in other studies $[18,19]$. Multiple Risk Factor Intervention Trial (MRFIT) found an increased risk for end-stage renal disease (ESRD) for smokers as compared to non-smokers $[20,21]$. Such increased relative risk of ESRD related to smoking (up to 1.69 for heavy smokers) was independent of age, ethnicity, income, blood pressure, diabetes mellitus, prior history of myocardial infarction, or serum cholesterol.

Smoking causes kidney deterioration in diabetic patients with adverse effects on four different aspects of albumin excretion: It increases the risk of microalbuminuria[5], shortens the time interval between onset of diabetes and onset of albuminuria or proteinuria [6,7], accelerates the rate of progression from microalbuminuria to persistent proteinuria [22,23], and accelerates the rate of progression of diabetic nephropathy to ESRD $[6,8]$. Chase et al. [5] reported that in a group of 359 young subjects with IDDM the prevalence of borderline (> $7.6 \mathrm{mcg} / \mathrm{min})$ and abnormal $(>30 \mathrm{mcg} / \mathrm{min}$ ) albumin excretion rate was 2.8 fold higher in smokers than in non-smokers. Sawicki et al. [24] calculated the adjusted odds ratio for the progression of diabetic nephropathy and found that the odds ratio was higher by a factor of 2.74 for each 10 pack/year smoking history. In this study all patients were administered an intensified insulin along with antihypertensive therapy so that the confounding effects of hyperglycemia and hypertension were minimized. Similar results were found by Biesenbach et al. [8] which concluded that the rate of loss of 
Table 3 Odds ratio for chronic renal failure by type among regular smokers

\begin{tabular}{|c|c|c|c|c|c|}
\hline & \multirow[t]{2}{*}{$N(\% *)$} & \multicolumn{2}{|c|}{ Ever regular use of cigarettes } & \multirow[t]{2}{*}{$\mathrm{OR}^{\dagger}(\mathrm{Cl} 95 \%)$} & \multirow[t]{2}{*}{$\mathbf{P}$} \\
\hline & & $\begin{array}{l}\text { No } \\
n\left(\%^{* *}\right)\end{array}$ & $\begin{array}{l}\text { Yes } \\
\text { n }(\%+)\end{array}$ & & \\
\hline Control & $371(65.2)$ & $120(51.7)$ & $251(74.5)$ & 1 Reference & - \\
\hline Glomerulonephritis & $90(15.8)$ & $59(25.4)$ & $31(9.1)$ & $1.09(0.67-1.78)$ & 0.7 \\
\hline Diabetic nephropathy & $56(9.8)$ & $27(11.6)$ & $29(8.6)$ & $2.24(1.27-3.96)$ & 0.005 \\
\hline Hypertension & $26(4.6)$ & $11(4.8)$ & $15(4.5)$ & $2.85(1.27-6.39)$ & 0.011 \\
\hline Unknown and other causes & $26(4.6)$ & $15(6.5)$ & $11(3.3)$ & $1.53(0.68-3.44)$ & 0.2 \\
\hline
\end{tabular}

*Of all subjects $(n=569) .{ }^{* *}$ Of never regular smokers $(n=232) .{ }^{+}$Of ever regular smokers $(n=337) .{ }^{\dagger}$ Adjusted by age and gender.

GFR was higher by a factor of 1.44 in smoking patients as compared to the non-smoking patients with insulin dependent diabetes mellitus (IDDM), and by a factor of 1.66 among NIDDM patients.

To determine the risk factors for noninsulin dependent diabetes in a cohort representative of middle aged British men, Perry et al. [25] conducted a prospective study on 7,735 males (40 to 59 years) and found that smoking was associated with a $50 \%$ increased risk of developing NIDDM. This increased risk may be related to the fact that smoking aggravates insulin resistance in healthy smokers [26].

Another question would be the effect of smoking cessation on kidney function. In patients with IDDM, Chase et al. [5] found that albuminuria improved significantly when patients stopped smoking. Sawicki et al. [24] studied 34 smokers, 35 nonsmokers, and 24 exsmokers with type I diabetes, hypertension, and diabetic nephropathy for one year and found that the progression of nephropathy was less common in nonsmokers (11\%) than in smokers (53\%) and in patients who had quit smoking (33\%). They also found that accumulated dose measured by pack/year was an independent predictive factor for the progression of diabetic nephropathy.

One of the other diseases that exacerbate with smoking is autosomal dominant polycystic kidney disease (ADPKD), Chapman et al. [27] found that ADPKD patients with established proteinuria had a greater pack/ year smoking history than their nonproteinuric counterparts did. Smoking is also responsible for renal function deterioration in lupus nephritis, as a retrospective cohort study of 160 adults found that smoking at the time of onset of nephritis was an independent risk factor for the more rapid development of ESRD [10]. The median time interval to terminal renal failure was 145 months in smokers, but more than 273 months in nonsmokers. These effects persisted in multivariable analyses adjusting for differences among patients in age, gender, socioeconomic status, renal histology, and immunosuppressive treatment. They also found that the combination of smoking and hypertension resulted in shorter times to renal failure compared with nonsmoking hypertensive patients. This observation was not found in another study conducted on 70 lupus nephritis patients [28].

Appel et al. [29] studied 45 patients each 50 years of age or older, beginning renal replacement therapy and found that smoking aggravates renal artery stenosis. This effect was explained by increased arthrogenesis among smokers. In their study Wang et al. [30] stated that there is different susceptibility to arthrogenesis among smokers, and that the risk appears to be excessively high in patients who are homozygous for the endothelial nitric oxide synthase 4 a (ecNOS4a) gene, which predisposes to endothelial dysfunction.

A previous, hospital-based case-control study [12] found a threefold increased risk for glomerulonephritis associated with CKD among heavy smokers while other studies did not find the same results. In a case-control study including 55 patients and 55 normal subjects Yaqoob et al. [31] reported that there was no significant correlation between tobacco and the development of primary glomerulonephritis. Merkel et al. [32] did not find any evidence that smoking aggravates the course of anti-glomerular basement membrane (anti-GBM) glomerulonephritis. Our study supports the observation made by Yaqoob regarding the association between smoking and the development of primary GN. However it was found that smoking is significantly associated with pulmonary hemorrhage in anti-GBM glomerulonephritis patients [33].

The increment of GFR induced by smoking may play a role in the genesis of hyperfiltration as a potential mediator of accelerated progression of chronic renal disease [34,35]. Pawlik et al. [36] studied renal excretory and circulatory responses to nicotine in anesthetized dogs and found that nicotine causes an increase in sodium and chloride excretion and urine flow, which is reversed after the administration of propranolol or in the group underwent adrenalectomy. This observation leads to a conclusion that nicotine action on the kidney is mediated by release of catecholamines from the adrenal medulla. Another mechanism could be the increment of vasopressin release secondary to altering 
cervical parasympathetic tone induced by nicotine, which increases GFR inappropriately $[37,38]$. On the other hand, the increment of GFR is thought to be due to an intermittent and persistent increase in blood pressure induced by smoking nicotine products; this blood pressure alteration was absent in patient smoking nicotine-free cigarettes [39-41].

Smoking also alters the proximal tubular function leading to increased excretion of $\mathrm{N}$-acetyl-f3-glucosaminidase (NAG) and impairment of organic cation transport [42] which correlates strongly with the amount of tobacco consumed [13].

\section{Conclusions}

In conclusion, our study found that smoking, particularly heavy smoking (> 30 pack/year), is an important risk factor to the development of CKD. The association was strongest for CKD classified as hypertension and diabetic nephropathy. These results raise the importance of smoking cessation to decrease the incidence of CKD and other preventable diseases as COPD, coronary artery diseases, and cancers.

\section{Acknowledgements}

Special thanks to Thomas DiNatale for his help.

\section{Author details \\ 'Internal Medicine department, University at Buffalo, Grider Street, Buffalo, N. Y. 14215, USA. ${ }^{2}$ Internal Medicine department, Seton Hall University, Pennington Harbourton Road, Pennington, N.J. 08534, USA. IInternal Medicine department, John H. Stroger, Jr. Hospital of Cook County, West Ogden Avenue, Chicago, IL. 60612, USA. ${ }^{4}$ Internal Medicine department, University of Aleppo, Almoohafaza Street, Aleppo. Syria.}

\section{Authors' contributions}

RY is the principle investigator, participated is study design, data analysis, data collection and manuscript preparation. $\mathrm{HH}$ participated on study design, data collection and manuscript preparation. AL participated in study design and manuscript preparation. RAA participated in data analysis and manuscript preparation. LV participated in data analysis and manuscript preparation. GA participated in data collection and manuscript preparation. NKA participated in data collection and manuscript preparation. SA participated in data collection. SAA participated in data collection. SAB is the supervisor, participated in study design and manuscript preparation. All authors read and approved the final manuscript.

\section{Competing interests}

The authors declare that they have no competing interests.

Received: 30 July 2010 Accepted: 25 November 2010 Published: 25 November 2010

\section{References}

1. Bleyer AJ, et al: Tobacco, hypertension, and vascular disease: risk factors for renal functional decline in an older population. Kidney Int 2000, 57(5):2072-9.

2. Yamagata $\mathrm{K}$, et al: Risk factors for chronic kidney disease in a community-based population: a 10-year follow-up study. Kidney Int 2007, 71(2):159-66.

3. Ejerblad $E$, et al: Association between smoking and chronic renal failure in a nationwide population-based case-control study. J Am Soc Nephrol 2004, 15(8):2178-85.
4. Deckert T, et al: Albuminuria reflects widespread vascular damage. The Steno hypothesis. Diabetologia 1989, 32(4):219-26.

5. Chase HP, et al: Cigarette smoking increases the risk of albuminuria among subjects with type I diabetes. JAMA 1991, 265(5):614-7.

6. Stegmayr B, Lithner F: Tobacco and end stage diabetic nephropathy. $\mathrm{Br}$ Med J (Clin Res Ed) 1987, 295(6598):581-2.

7. Stegmayr BG: A study of patients with diabetes mellitus (type 1) and end-stage renal failure: tobacco usage may increase risk of nephropathy and death. J Intern Med 1990, 228(2):121-4.

8. Biesenbach $G$, Janko O, Zazgornik J: Similar rate of progression in the predialysis phase in type I and type II diabetes mellitus. Nephrol Dial Transplant 1994, 9(8):1097-102.

9. Klein R, Klein BE, Moss SE: Incidence of gross proteinuria in older-onset diabetes. A population-based perspective. Diabetes 1993, 42(3):381-9.

10. Ward MM, Studenski S: Clinical prognostic factors in lupus nephritis. The importance of hypertension and smoking. Arch Intern Med 1992, 152(10):2082-8.

11. Orth $S R$, et al: Smoking as a risk factor for end-stage renal failure in men with primary renal disease. Kidney Int 1998, 54(3):926-31.

12. Stengel B, et al: Age, blood pressure and smoking effects on chronic renal failure in primary glomerular nephropathies. Kidney Int 2000 57(6):2519-26.

13. Hultberg $B$, et al: Elevated urinary excretion of beta-hexosaminidase in smokers. Eur J Clin Chem Clin Biochem 1992, 30(3):131-3.

14. Buchet JP, et al: Renal effects of cadmium body burden of the general population. Lancet 1990, 336(8717):699-702.

15. K/DOQI clinical practice guidelines for chronic kidney disease: evaluation, classification, and stratification. Am J Kidney Dis 2002, 39(2 Suppl 1):S1-266.

16. Larson TS: Evaluation of proteinuria. Mayo Clin Proc 1994, 69(12):1154-8.

17. Mimran $A$, et al: Albuminuria in normals and essential hypertension. $J$ Diabetes Complications 1994, 8(3):150-6.

18. Dales $L G$, et al: Cigarette smoking habits and urine characteristics: urinalysis abnormalities are more common is smokers, but the reasons are unclear. Nephron 1978, 20(3):167-70.

19. Bruno G, et al: Prevalence and risk factors for micro- and macroalbuminuria in an Italian population-based cohort of NIDDM subjects. Diabetes Care 1996, 19(1):43-7.

20. Brancati $F L$, et al: Risk of end-stage renal disease in diabetes mellitus: a prospective cohort study of men screened for MRFIT. Multiple Risk Factor Intervention Trial. JAMA 1997, 278(23):2069-74.

21. Klag MJ, et al: End-stage renal disease in African-American and white men. 16-year MRFIT findings. JAMA 1997, 277(16):1293-8.

22. Muhlhauser I, Sawicki P, Berger M: Cigarette-smoking as a risk factor for macroproteinuria and proliferative retinopathy in type 1 (insulindependent) diabetes. Diabetologia 1986, 29(8):500-2.

23. Telmer S, et al: Smoking habits and prevalence of clinical diabetic microangiopathy in insulin-dependent diabetics. Acta Med Scand 1984, 215(1):63-8

24. Sawicki PT, et al: Smoking is associated with progression of diabetic nephropathy. Diabetes Care 1994, 17(2):126-31.

25. Perry IJ, et al: Prospective study of risk factors for development of noninsulin dependent diabetes in middle aged British men. BMJ 1995, 310(6979):560-4.

26. Orth SR, Ritz E, Schrier RW: The renal risks of smoking. Kidney Int 1997, 51(6):1669-77.

27. Chapman $A B$, et al: Overt proteinuria and microalbuminuria in autosomal dominant polycystic kidney disease. J Am Soc Nephrol 1994, 5(6):1349-54

28. Font J, et al: Cardiovascular risk factors and the long-term outcome of lupus nephritis. QJM 2001, 94(1):19-26.

29. Appel RG, et al: Renovascular disease in older patients beginning renal replacement therapy. Kidney Int 1995, 48(1):171-6.

30. Wang $\mathrm{XL}$, et al: A smoking-dependent risk of coronary artery disease associated with a polymorphism of the endothelial nitric oxide synthase gene. Nat Med 1996, 2(1):41-5.

31. Yaqoob M, et al: Primary glomerulonephritis and hydrocarbon exposure: a case-control study and literature review. Q J Med 1992, 83(301):409-18.

32. Merkel F, et al: Course and prognosis of anti-basement membrane antibody (anti-BM-Ab)-mediated disease: report of 35 cases. Nephrol Dial Transplant 1994, 9(4):372-6. 
33. Herody M, et al: Anti-GBM disease: predictive value of clinical, histological and serological data. Clin Nephrol 1993, 40(5):249-55.

34. Neuringer JR, Brenner BM: Hemodynamic theory of progressive renal disease: a 10-year update in brief review. Am J Kidney Dis 1993, 22(1):98-104.

35. Hostetter TH: Progression of renal disease and renal hypertrophy. Annu Rev Physiol 1995, 57:263-78.

36. Pawlik WW, Jacobson ED, Banks RO: Actions of nicotine on renal function in dogs. Proc Soc Exp Biol Med 1985, 178(4):585-90

37. Cadnapaphornchai $P$, et al: Mechanism of effect of nicotine on renal water excretion. Am J Physiol 1974, 227(5):1216-20.

38. Bankir L, Bouby N: Vasopressin and urinary concentration: additional risk factors in the progression of chronic renal failure. Am J Kidney Dis 1991, 17(5 Suppl 1):20-6.

39. Aronow WS, Swanson AJ: Non-nicotinized cigarettes and angina pectoris. Ann Intern Med 1969, 70(6):1227.

40. Aronow WS, Rokaw SN: Carboxyhemoglobin caused by smoking nonnicotine cigarettes. Effects in angina pectoris. Circulation 1971 44(5):782-8.

41. Aronow WS, Dendinger J, Rokaw SN: Heart rate and carbon monoxide level after smoking high-, low-, and non-nicotine cigarettes. A study in male patients with angina pectoris. Ann Intern Med 1971, 74(5):697-702.

42. Wong LT, Smyth DD, Sitar DS: Interference with renal organic cation transport by (-)- and (+)-nicotine at concentrations documented in plasma of habitual tobacco smokers. J Pharmacol Exp Ther 1992, 261(1):21-5.

\section{Pre-publication history}

The pre-publication history for this paper can be accessed here: http://www.biomedcentral.com/1471-2458/10/731/prepub

doi:10.1186/1471-2458-10-731

Cite this article as: Yacoub et al: Association between smoking and chronic kidney disease: a case control study. BMC Public Health 2010 10:731.

\section{Submit your next manuscript to BioMed Central} and take full advantage of:

- Convenient online submission

- Thorough peer review

- No space constraints or color figure charges

- Immediate publication on acceptance

- Inclusion in PubMed, CAS, Scopus and Google Scholar

- Research which is freely available for redistribution 